\title{
USO DA METODOLOGIA DA PROBLEMATIZAÇÃO NA FORMAÇÃO DO ENGENHEIRO AGRÔNOMO
}

\author{
G. R. O. REGO ${ }^{1}$ \& GAMARRA-ROJAS, G $^{2}$
}

${ }^{1}$ Gradundo em Agronomia pela Universidade Federal do Ceará. E-mail: gleydysonricarte @ hotmail.com; 2 Professor associado da Universidade Federal do Ceará, onde leciona e orienta nos Cursos de Graduação das Ciências Agrárias (Agronomia, Economia Ecológica, Engenharia de Pesca e Zootecnia) e no Programa de Pós-Graduação em Economia Rural. Atua nas áreas de Agroecologia e Extensão Rural tem experiência em elaboração e coordenação de projetos de pesquisa e desenvolvimento, extensão e formação profissional. E-mail: ggamarra@terrra.com.br.

Artigo submetido em setembro de 2019 - DOI 10.32356/exta.v19.n1.42139

\section{RESUMO}

O trabalho discute resultados de um estudo qualitativo realizado em 2016 com 15 estudantes da disciplina de Aspectos Sociais da Agricultura do bacharelado em Agronomia da Universidade Federal do Ceará. Teve por objetivo analisar a apreensão, percepção e aceitação por parte dos discentes à metodologia da problematização, entendida como um instrumento metodológico para a formação do profissional de ciências agrárias atingir o perfil profissional nas diversas dimensões necessárias à sua atuação. $\mathrm{O}$ estudo foi realizado durante as aulas da referida disciplina, através da observação das atividades desenvolvidas, seguida de avaliações na forma de seminários. A fim de avaliar a percepção dos estudantes foi aplicado um questionário, respondido por 13 dos participantes. Utilizou-se a análise de conteúdo como ferramenta de análise. Como resultado, foi possível concluir que os estudantes avaliaram a experiência como positiva, indicando que a problematização é uma metodologia promissora para o ensinoaprendizagem, capaz de aliar teoria e prática, e eficiente para formar um profissional mais sensível e adaptado às diversas realidades agrárias e agrícolas. São apontadas dificuldades com a adaptação à metodologia, sugerindo a necessidade de se realizar um melhor planejamento e dimensionamento das aulas.

PALAVRAS-CHAVE: Ensino. Métodos Didático-pedagógicos. Metodologias ativas.

\section{USE OF THE PROBLEMATIZATION METHODOLOGY IN THE QUALIFICATION OF THE AGRONOMIST}

\begin{abstract}
The paper discusses the results of a qualitative study carried out in 2016 with students of the Social Aspects of Agriculture discipline from the bachelor's degree in Agronomy at the Federal University of Ceará. It aimed to analyze the apprehension, perception and acceptance by students of the problematization methodology, considered as a methodological instrument for the training of agricultural sciences professionals to reach the professional profile in the various dimensions necessary for their performance. The study was carried out during the classes of the above cited discipline, through the observation of the activities developed, followed by evaluations in the form of seminars. It was applied a questionnaire in
\end{abstract}

order to assess the perception of students. Thirteen of them attended to the request. It was used the Content analysis methodology as an analysis tool. As a result, it is concluded that the students evaluated the experience as positive, indicating that problematization is a promising methodology for teaching-learning, capable of combining theory and practice, and efficient to form a more sensitive professional and adapted to the diverse agrarian and agricultural realities. Students outlined difficulties to adapt to the 'new' methodology, suggesting the need to carry out better planning and dimensioning of classes.

KEYWORDS: Education. Didactic-pedagogical methods. Active methodologies. 


\section{INTRODUÇÃO}

A agronomia surge como a ciência capaz de resolver os problemas essenciais do campo, que entravam seu desenvolvimento. O olhar holístico da realidade é essencial para o profissional da agronomia no tratar dos problemas que surgem diariamente no campo. Apesar disso, a formação oferecida pelos cursos de agronomia ainda conserva seus primórdios, o que não atende à demanda do campo. Segundo Cavallet (1999. p. 97), a formação profissional do Engenheiro Agrônomo atual continua a ser efetuada visando um profissional direcionado à busca da eficiência produtiva como fim, de acordo com os objetivos do setor de agronegócios a quem serve prioritariamente. Para o autor, é demandado desse profissional ferramentas que possibilitem um entendimento amplo e plural da realidade, aliado com os aspectos técnicos que envolvem a agricultura e não só isso, mas também outras interações, desdobramentos e necessidades do meio agrário. De acordo com Barrios et al. (2014, p. 30), ao concluir o curso [os agrônomos] deverão estar preparados para agir, inovar e transformar as sociedades futuras onde encontrarão novos desafios.

Formar um agrônomo com tais qualidades requer a utilização de métodos de ensinoaprendizagem que desenvolvam neste profissional competências de observação da realidade de uma maneira holística, onde se podem considerar todos os elementos que formam interativamente a realidade rural. Deve-se, em complemento às atividades tradicionais, incorporar às disciplinas metodologias de ensino-aprendizagem que desenvolvam profissionais aptos e sensíveis a uma realidade complexa, e não segmentada, como se concebe atualmente.

Estas metodologias, colocadas por Diaz Bordenave e Pereira (1977, p. 10) como componentes de uma educação libertadora, preconizam que a aprendizagem é concebida como a resposta natural do estudante ao desafio de uma situação-problema. $\mathrm{O}$ estudante passa a ter de uma visão global do problema a uma visão analítica do mesmo para chegar a uma síntese provisória, que equivale a compreensão. Desta apreensão ampla e profunda da estrutura dos problemas e de suas consequências nascem hipóteses de solução que obrigam a uma seleção das soluções mais viáveis. A síntese tem continuidade na práxis, isto é, na atividade transformadora da realidade.

As limitações do modo convencional de ensino-aprendizagem nos cursos de bacharelado das Ciências Agrárias são percebidas por docentes e discentes e tem motivado a 
experimentação de metodologias sociocríticas inovadoras na Universidade Federal do Ceará, tais como a Metodologia da Problematização.

A metodologia da problematização emerge das correntes pedagógicas pós-modernas que, segundo Libâneo (2009), fazem a crítica às pedagogias da modernidade, quando prevaleceram na educação os enfoques pautados na preparação de profissionais para assumirem as exigências de produtividade e reprodução do capital. A mesma faz parte das metodologias de aprendizagem experiencial (Kolb, 1984) e crítico problematizadora (Saviani, 1999), onde a educação é concebida como processo de compreensão da realidade para a sua transformação, que surge da observação de uma realidade e culmina na aplicação de soluções a esta mesma realidade.

Para Marin et al. (2010, p. 16), tais metodologias ativas de aprendizagem estimulam o estudo constante, a independência e a responsabilidade do estudante, o que vem ao encontro das ideias de Paulo Freire quando afirma que o conhecimento só pode ser desenvolvido na própria ação do indivíduo. Diaz Bordenave e Pereira (1977, p. 10) afirmam que uma pessoa só conhece bem algo quando o transforma, transformando-se ela também no processo.

Duas metodologias problematizadoras vêm se destacando em instituições do ensino superior nos últimos anos: a Aprendizagem Baseada em Problemas e a Metodologia da Problematização. Berbel (1998) faz uma distinção didática entre ambas. Na primeira os problemas de ensino são elaborados por uma equipe de especialistas para cobrir todos os conhecimentos essenciais do currículo. $\mathrm{Na}$ segunda os problemas são extraídos da realidade pela observação realizada pelos estudantes. Para Berbel $(1995$, p. 11) a problematização não parte de um problema qualquer, ou imaginado pelo professor para estimular o potencial intelectual do aluno, mas de problemas reais, percebidos pela observação direta da realidade em foco.

Explicar a metodologia da problematização torna-se mais factível utilizando o esquema do arco, proposto por Charles Margarez. Segundo Diaz Bordenave e Pereira (1977, p. 13), este esquema pedagógico começa com a exposição dos alunos a um problema, que é parte integrante da realidade física ou social. A esta etapa admite-se chamar de OBSERVAÇÃO DA REALIDADE e consiste numa visão mais geral do problema. Uma vez observada a realidade, a segunda etapa consiste em identificar PONTOS-CHAVE, nos quais mudanças precisam serem feitas para promover uma transformação significativa da realidade. Na terceira fase, a da 
TEORIZAÇÃO, o estudante busca o entendimento da realidade através de questionamentos, através de responder o porquê das coisas observadas. Feita a teorização, quando bem-sucedida, têm-se o entendimento da realidade observada. Pode-se então, formular HIPÓTESES DE SOLUÇÃO aos problemas-chave. Neste momento se estuda a viabilidade das hipóteses levantadas, escolhendo as mais viáveis para se chegar à transformação da realidade. A última fase é a APLICAÇÃO À REALIDADE, onde findado o processo, o estudante foi capaz de observar holisticamente a realidade, identificar pontos que são chaves, entender as causas que limitam seu desenvolvimento, e aplicar soluções construídas em torno do conhecimento gerado durante todo este processo.

Para Marin et al. (2010, p. 17), 'esta metodologia contribui para uma compreensão ampla e integrada da diversidade das necessidades encontradas no cotidiano dos profissionais. Em contato com a realidade, os estudantes identificam situações-problema concretas, possibilitam a construção de novos sentidos e implicam o conhecimento com o seu meio. Desse modo, produzem respostas com seus estudos, visando aplicar os conhecimentos à solução dos problemas vivenciados'.

Contudo, segundo Marin et al. (2010, p. 17), podem existir algumas fragilidades no uso de metodologias ativas de aprendizagem, principalmente quando há uma mudança abrupta das metodologias tradicionais para a metodologia da problematização, por exemplo. Os estudantes sentem-se perdidos na busca de conhecimento, principalmente em disciplinas básicas. Esta mudança abrupta gera nos estudantes insegurança, requer grande esforço dos atores envolvidos no processo e exige mudança de comportamento, maturidade e organização dos estudantes. Os condutores do processo de aprendizagem devem estar bem fundamentados e familiarizados com a metodologia e deve haver constante empenho na revisão dos processos utilizados, de forma a confrontar fortalezas e fragilidades, com vistas a seu aperfeiçoamento.

Segundo Berbel (2012, p. 1), a primeira etapa da Metodologia da Problematização, que consiste na formulação do problema, é a que tem constituído o maior desafio. Talvez se deva à insegurança em se saber quando se está diante de um problema ou não e se o mesmo é relevante. Para Berbel (2012, p. 1) a insegurança de que falamos pode se dar por várias razões e uma delas seria porque não fomos acostumados, através de escolaridade regular, a formular problemas, a problematizar. O problema, em geral, surge de algo que necessita ser superado, de uma dificuldade tal que, para dar uma resposta, será preciso reunir uma série de elementos, 
principalmente porque, através da Metodologia da Problematização, o problema não é algo abstrato; é algo extraído da realidade observada. Então, dificilmente vamos encontrar uma resposta pronta para um problema que estamos encontrando neste momento, nesta realidade.

Desse modo, o objetivo do trabalho foi analisar a apreensão, percepção e aceitação dos estudantes de agronomia à metodologia da problematização, sendo um instrumento metodológico para a formação do profissional de ciências agrárias.

\title{
PROCEDIMENTOS METODOLÓGICOS
}

\section{Natureza e tipo da pesquisa}

Trata-se de um estudo de caso, baseado na abordagem qualitativa, na qual, segundo Prodanov e Freitas (2013, p. 70):

\begin{abstract}
há uma relação dinâmica entre o mundo real e o sujeito, isto é, um vínculo indissociável entre o mundo objetivo e a subjetividade do sujeito que não pode ser traduzido em números. A interpretação dos fenômenos e a atribuição de significados são básicas no processo de pesquisa qualitativa. Esta não requer o uso de métodos e técnicas estatísticas. $\mathrm{O}$ ambiente natural é a fonte direta para coleta de dados e o pesquisador é o instrumento-chave. Tal pesquisa é descritiva. Os pesquisadores tendem a analisar seus dados indutivamente. O processo e seu significado são os focos principais de abordagem.
\end{abstract}

Foi utilizado como técnica a observação, realizando-se apontamentos no decorrer das aulas da disciplina, pela análise dos documentos gerados durante as atividades e do questionário. Este último foi apresentado escrito, de forma impressa, contendo quatro questões abertas.

\section{Sujeitos, local e época de realização da pesquisa}

Desenvolveu-se no primeiro semestre do ano de 2016 com a turma da disciplina de Aspectos Sociais da Agricultura, composta por 15 estudantes, a qual é ofertada no $5^{\circ}$ semestre do Curso de Agronomia pelo setor de estudo de Extensão Rural do Departamento de Economia Agrícola da Universidade Federal do Ceará (UFC). Nesta fase da graduação, os estudantes já cursaram as disciplinas de conteúdos de conhecimentos gerais básicos, mas ainda estão iniciando o estudo de disciplinas de conteúdos profissionalizantes.

\section{Aplicação da metodologia da problematização}

A aplicação da metodologia pelos estudantes constou de cinco etapas, quais sejam: 
i.Preparação teórico-metodológica - Inicialmente apresentou-se à turma a metodologia da problematização, expondo e discutindo os seus fundamentos e etapas. Seguidamente, fez-se uma breve descrição das realidades a serem observadas em campo, quais sejam: o Horto de Plantas Medicinais da Universidade Federal do Ceará e o horto do Movimento Mulheres de Itaoca, no bairro da Parangaba, em Fortaleza. A escolha desses hortos para o trabalho de campo se deve ao fato de serem formas de agricultura urbana ou agroecossistemas, com os quais os estudantes de agronomia usualmente se sentem motivados a interagir e podem exercitar as competências adquiridas durante a graduação. Finalizando a etapa preparatória foi apresentado e discutido um roteiro para observação do agroecossistema, adaptado das Escolas do Campo de Gallagher (2003), a qual também segue uma perspectiva problematizadora.

ii.Observação do Agroecossistema - os estudantes realizaram visitas de aproximadamente duas horas de duração aos hortos, em dias separados. Seguindo o roteiro para observação do agroecossistema os mesmos se dividiram em grupos de cinco pessoas e interagiram com os gestores desses agroecossistemas enquanto realizavam um percurso pelas áreas de cultivo e de transformação da produção formulando perguntas sobre as atividades de manejo, administração, comercialização etc., e fazendo registros por meio de fotografias, gravações e anotações.

iii.Análise do sistema - Após a visita, cada subgrupo fez uma descrição visual e escrita do agroecossistema, no qual se analisou e discutiu as decisões de manejo, administração etc. Finalizaram fazendo um balanço dos pontos críticos (positivos e negativos) do sistema.

iv.Apresentação dos resultados da observação do sistema - Cada subgrupo apresentou os seus resultados à turma, explorando os pontos críticos e discutindo temas a serem aprofundados conceitual e teoricamente.

v.Seminários - Envolveu a revisão bibliográfica e conceitual dos assuntos (temas) escolhidos pelo subgrupo gerando como produto desta atividade relatórios e uma apresentação na forma de seminário em que se apresentaram propostas para superação das limitações e/ou aproveitamento de oportunidades.

\section{Análise da Percepção sobre a Metodologia da Problematização}

Para avaliar a experiência com a metodologia, foi elaborado e aplicado um questionário aberto contendo as quatro questões abaixo listadas. Do total de quinze participantes, treze $(86,7 \%)$ estudantes responderam livremente ao questionário. Além das quatro primeiras questões - relativas à apreensão, percepção e aceitação da metodologia pelos estudantes - foi adicionada uma quinta questão, tendo em vista que o uso da metodologia da problematização, planejada inicialmente para ser utilizada durante toda a disciplina, foi interrompida a pedido dos estudantes. Esta última questão buscou analisar os motivos dessa desistência.

i.'Na sua compreensão, qual(is) a(s) ideia(s) principal(is) da Metodologia da Problematização?'

ii. 'Que contribuição você acha que a atividade realizada acrescentou ao seu aprendizado na disciplina?' 
iii.'Você acredita que a Educação Problematizadora é capaz de formar um profissional/cidadão de forma mais completa? Explique;

iv. 'Se tivesse a oportunidade, em alguma outra disciplina, teria interesse em aplicar novamente a Metodologia da Problematização?'

v. 'Qual o principal fator que o motivou a optar por desistir de levar a Metodologia até o fim no exercício?'

As respostas do questionário foram organizadas e analisadas seguindo a metodologia da análise de conteúdo do tipo categorial, adaptada de Bardin (1977), que consiste em um método de análise qualitativa que tem por objetivos ultrapassar as incertezas, quando tenta reduzir a subjetividade daquele que analisa os dados e o enriquecimento da leitura, pela descoberta de conteúdos e de estruturas que confirmam o que se procura demonstrar ou conduzir a elementos sutis, de que antes não se mostravam claros.

Portanto, seguindo os passos metodológicos, foi realizada uma pré-análise do material obtido, utilizando uma leitura flutuante, organizando os dados de uma maneira mais inteligível e selecionando o que realmente seria de interesse para as análises. O material foi organizado obedecendo a temática das questões, que estavam alinhadas com os objetivos da pesquisa. Logo, foram definidas as 5 categorias a serem analisadas. A fase seguinte foi realizar a codificação das ideias centrais que surgem dentro do texto. Essas ideias são, assim, destacadas e reservadas para a fase seguinte da análise. Posteriormente, foi realizado o agrupamento das ideias que são convergentes, criando uma subcategorização dos resultados. A partir das subcategorias, foram feitas as inferências relacionadas aos dados obtidos, obtendo os resultados da análise e realizando a discussão com a literatura.

\section{RESULTADOS E DISCUSSÃO}

A Análise de Conteúdo aplicada às respostas ao questionário aberto com o propósito de captar a percepção dos estudantes sobre a experiência do uso da Metodologia da problematização durante a disciplina de Aspectos Sociais da Agricultura retornou os seguintes resultados, organizados em cinco categorias temáticas e respectivas subcategorias (Quadro 1). 
QUADRO 1 - Percepção dos estudantes sobre o uso da metodologia da Problematização

\begin{tabular}{|c|c|c|}
\hline \multicolumn{2}{|c|}{ DISCURSOS CONTIDOS NAS RESPOSTAS } & \multirow{2}{*}{$\begin{array}{l}\text { FREQUÊNCIA } \\
\text { ABSOLUTA }\end{array}$} \\
\hline CATEGORIAS & SUBCATEGORIAS & \\
\hline \multirow[t]{5}{*}{ Ideias Principais da Metodologia } & Obtenção de soluções práticas & 8 \\
\hline & $\begin{array}{l}\text { Conhecer e compreender a } \\
\text { realidade. }\end{array}$ & 4 \\
\hline & Aprendizagem crítica. & 3 \\
\hline & $\begin{array}{l}\text { Aprendizagem a partir da } \\
\text { experiência. }\end{array}$ & 1 \\
\hline & $\begin{array}{l}\text { Aprendizagem aliando teoria e } \\
\text { prática. }\end{array}$ & 1 \\
\hline \multirow{5}{*}{$\begin{array}{l}\text { Contribuições da Metodologia para a } \\
\text { Disciplina }\end{array}$} & Melhor percepção da realidade. & 5 \\
\hline & Desenvolveu o senso crítico. & 4 \\
\hline & $\begin{array}{l}\text { Uma maneira diferente de se } \\
\text { trabalhar, pesquisar. }\end{array}$ & 2 \\
\hline & $\begin{array}{l}\text { A noção de que problema é diferente } \\
\text { de dificuldade. }\end{array}$ & 1 \\
\hline & Permite avaliar aspectos sociais. & 1 \\
\hline
\end{tabular}

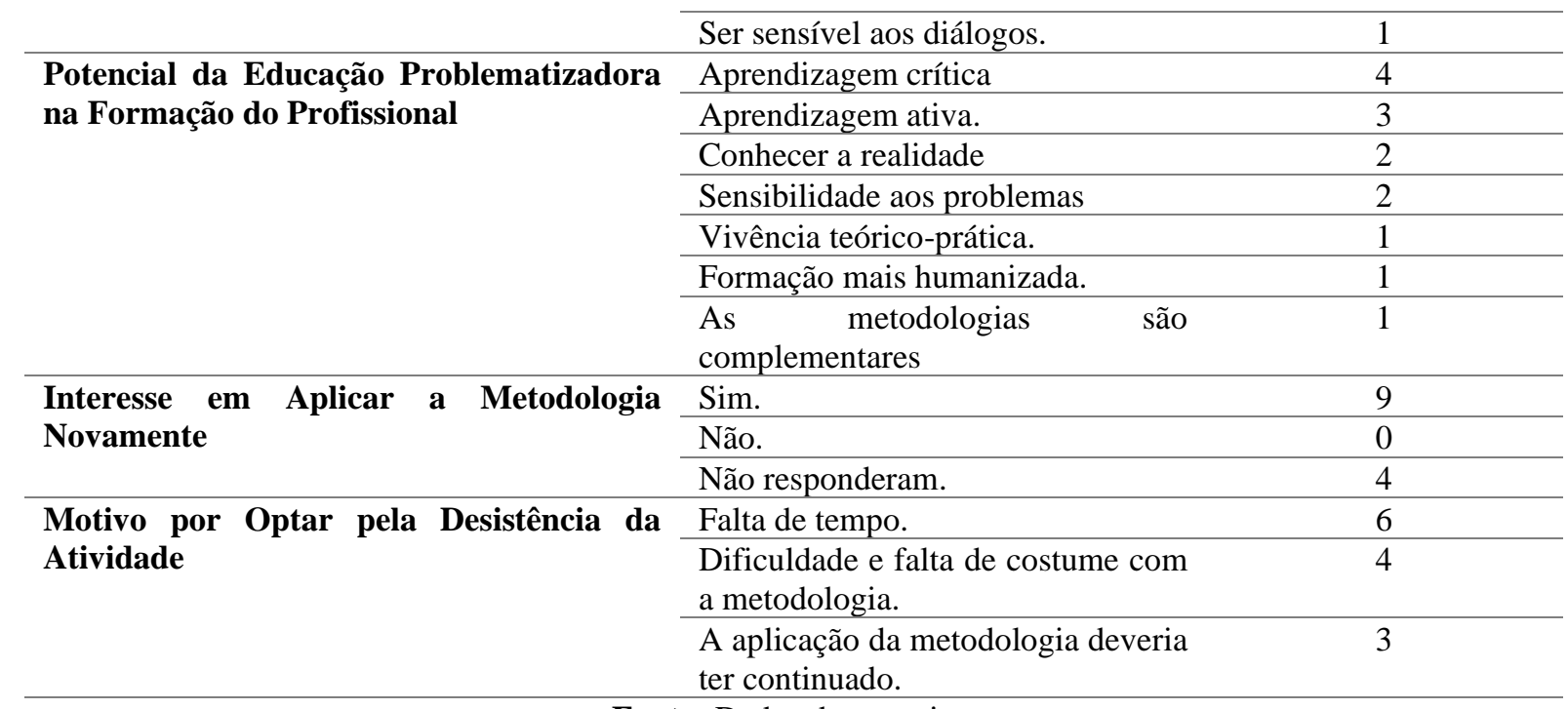

Fonte: Dados da pesquisa.

Dos 13 estudantes que participaram da pesquisa, 8 indicaram que a ideia principal da Metodologia da Problematização é obter soluções práticas através da observação de uma realidade. Um dos estudantes relatou que "A ideia principal é conseguir soluções práticas para um determinado problema de um sistema através da observação da realidade do mesmo." (I). 
Outro disse que "Através de visitas e observações com a utilização de parâmetros de comparação, detectar e avaliar questões que possam ser melhoradas, criando assim a problematização da situação." (II). É possível compreender que os estudantes tomaram a metodologia como uma ferramenta de trabalho, que pode ser utilizada na solução de problemas reais, tanto como ferramenta de aprendizagem, como em situações profissionais. Para Berbel (2011, p. 29):

podemos entender que as Metodologias Ativas baseiam-se em formas de desenvolver o processo de aprender, utilizando experiências reais ou simuladas, visando às condições de solucionar, com sucesso, desafios advindos das atividades essenciais da prática social, em diferentes contextos.

Para 4 dos 13 dos estudantes, a metodologia permite conhecer e compreender a realidade. Berbel (1995, p. 12) afirma que o confronto entre a percepção primeira dos aprendizes com o conhecimento já elaborado permite uma análise e compreensão mais profunda, lógica e porque não dizer científica do que acontece na realidade, para se chegar à transformação dos sujeitos e consequentemente da própria realidade. Para o profissional das ciências agrárias, conhecer bem a realidade antes de realizar qualquer intervenção é essencial. Esta intervenção tem consequências sobre o ambiente, a estrutura social e financeira dos envolvidos. A Metodologia da Problematização com o Arco de Marguerez permite que se adquira o cuidado de observar, estudar e discutir com os envolvidos, buscar informações em diversas fontes e, então, elaborar formas de intervenção. Este comportamento, sendo levado para o campo profissional, permite que as ações adotadas possam ser as mais acertadas possíveis. Ao utilizar a metodologia, os estudantes perceberam essa potencialidade, já que um deles afirma que a metodologia tem como ideia principal "ter uma abordagem mais completa [da realidade], analisando a fundo tudo o que pode ser apontado como problema ou oportunidade para assim ter uma gama maior e mais elaborada de alternativas como solução". (V).

Como abordado anteriormente, é essencial ter uma visão crítica sobre a realidade e o que se está fazendo dentro deste contexto. Três dos estudantes entrevistados citam que a metodologia promove uma aprendizagem que instiga a criticidade do estudante. Vasconcellos (1999, p. 31) afirma que é necessário utilizar metodologias que possibilitem a formação de um profissional crítico, capaz de identificar as determinantes sociais mais amplas que condicionam sua prática, e as condições materiais, capaz de criticar e transformar o cotidiano. Um dos estudantes menciona que "a Metodologia da Problematização tem como ideia principal discutir 
determinado assunto fazendo com que o indivíduo desenvolva um pensamento crítico sobre tal, buscando alcançar um problema central." (IX).

Segundo Berbel (2011, p. 34)

\begin{abstract}
Todas as alternativas de metodologias ativas (...) colocam o aluno diante de problemas e/ou desafios que mobilizam o seu potencial intelectual, enquanto estuda para compreendê-los e ou superá-los. Os estudantes necessitam de informações, mas são especialmente estimulados a trabalhar com elas, elaborá-las e reelaborá-las em função do que precisam responder ou equacionar. Nesse caminho, é possível que ocorra, gradativamente, o desenvolvimento do espírito científico, do pensamento crítico, do pensamento reflexivo, de valores éticos, entre outras conquistas dessa natureza, por meio da educação, nos diferentes níveis, contribuindo para o desenvolvimento da autonomia na formação do ser humano e de futuros profissionais.
\end{abstract}

Também foi citado por um estudante que a Metodologia da Problematização possibilita a aprendizagem a partir de conhecimentos prévios. Melo \& Santana (2012, p. 330) colocam que a problematização (...) utiliza o esquema do Método do Arco, de Charles Marguerez, que considera como pré-requisito da educação a realidade do indivíduo, suas vivências e experiências, seus saberes e conhecimentos prévios. Essa característica é essencial para as metodologias ativas, que preconizam que a aprendizagem só é concreta a partir das experiências anteriores do indivíduo, que vão se transformando com ele à medida que o conhecimento é gerado através do ato de aprender.

Foi lembrado também como característica principal da Metodologia em um dos 13 respondentes, a aprendizagem aliando teoria e prática. Marin et al. (2010, p. 17) afirma que

\begin{abstract}
[A metodologia da problematização](...)contribui para a aproximação ensino/serviço e para uma compreensão ampliada e integrada da diversidade das necessidades encontradas no cotidiano dos profissionais de saúde. Em contato com a realidade, os estudantes identificam situações-problema concretas, que possibilitam a construção de novos sentidos e implicam compromisso com o seu meio. Desse modo, produzem respostas com seus estudos, visando aplicar os conhecimentos à solução dos problemas vivenciados. Acrescente-se que a reflexão crítica sobre a prática, no sentido de captar seus avanços, resistências e dificuldades, possibilita a tomada de decisão sobre o que fazer para superar obstáculos.
\end{abstract}

O que evidenciaram Marin et al. (2010) para a área da saúde não difere do profissional de Ciências Agrárias. Este também atua como um agente de promoção social, intervindo diretamente na vida e cotidiano dos agricultores, independentemente do nível de ação deste profissional, seja no planejamento de Políticas Públicas, seja diretamente no campo em ações extensionistas. $\mathrm{O}$ contato do profissional com a realidade ainda como estudante promove um impacto essencial para sua formação, permitindo a este perceber o que é requerido dele quando for profissional. 
O gráfico abaixo (Gráfico 1) evidencia não só como foram entendidos pelos estudantes os objetivos de se utilizar esta abordagem, mas as que impactaram um maior número de pessoas ao entrar em contato com a metodologia. A partir disso é possível dizer que os estudantes assimilaram a metodologia da problematização como uma ferramenta de construção do aprendizado que supre uma lacuna na formação, que é a solução dos problemas que surgem a partir da prática e o contato com uma realidade.

GRÁFICO 1 - Percepção dos estudantes quanto às ideias principais da Metodologia

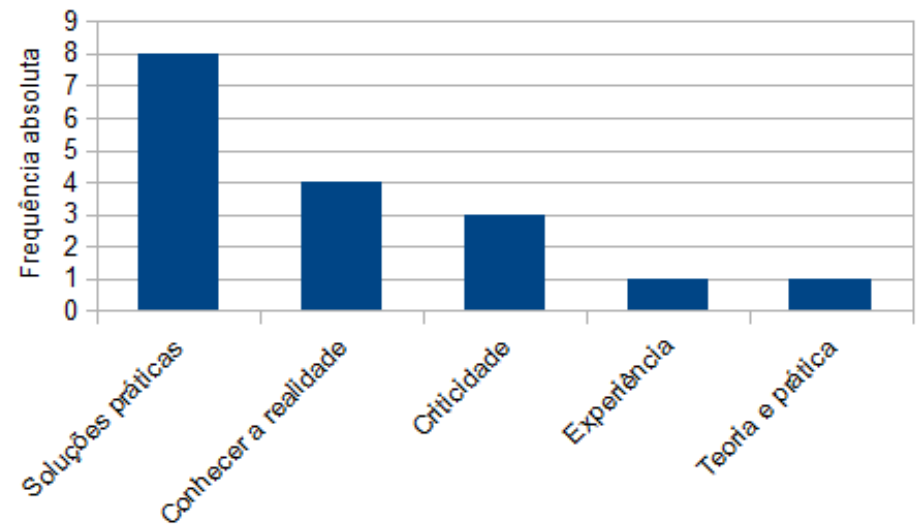

Quanto às contribuições que a utilização da Metodologia da Problematização trouxe à disciplina de Aspectos Sociais da Agricultura, os estudantes citam que a mesma proporciona uma melhor percepção da realidade, desenvolve o senso crítico, fornece uma nova abordagem de trabalho e pesquisa, permite avaliar aspectos sociais, proporciona maior sensibilidade aos diálogos. 
GRÁFICO 2 - Contribuições da Metodologia para a disciplina

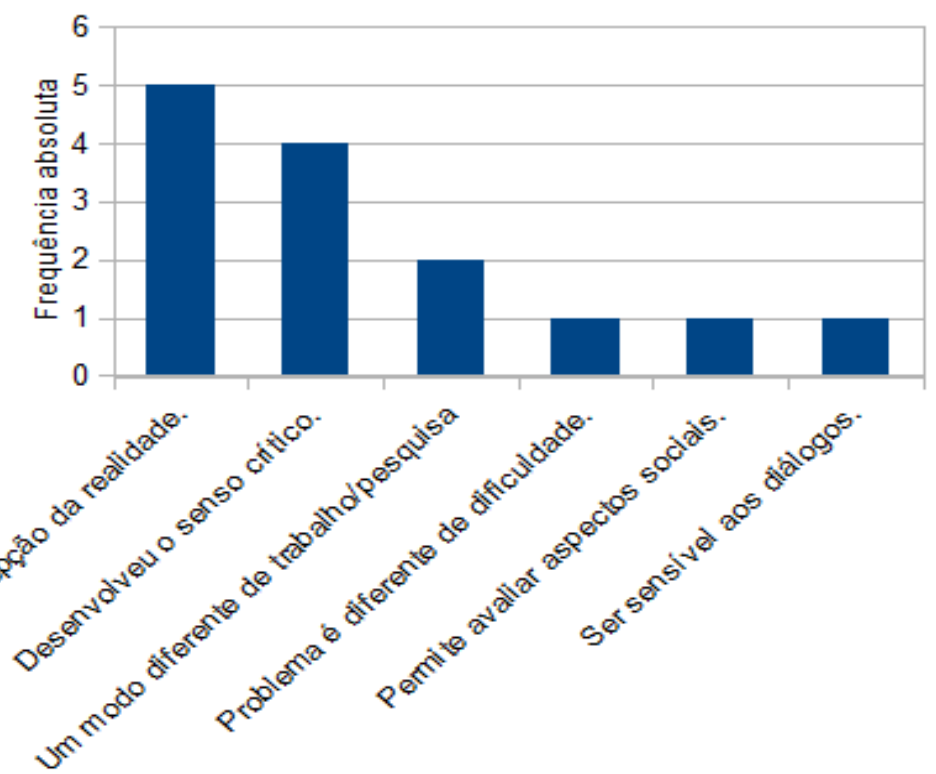

O benefício mais marcante trazido à disciplina foi a capacidade de perceber e entender a realidade à volta, característica importante para um profissional do qual se espera manusear os recursos naturais e materiais existentes em um agroecossistema, objetivando a otimização desses recursos. Apenas com um olhar atento e um bom entendimento de seu entorno, é possível agir positivamente dentro de tal intervenção.

Quanto ao potencial da Metodologia na Formação do Profissional de Ciências Agrárias (Gráfico 3), os estudantes indicam de forma positiva que a metodologia desenvolve habilidades essenciais. Para 4 de 13 dos estudantes, desenvolve uma aprendizagem mais crítica. Esta característica é essencial para este profissional, como já discutimos anteriormente, assim como a eficiência e clara percepção pelos estudantes sobre o potencial desta abordagem nesse sentido. Três de 13 indicam que motiva e instiga a um protagonismo frente ao ato de estudar. 
GRÁFICO 3 - Potencial da Educação Problematizadora na Formação do Profissional

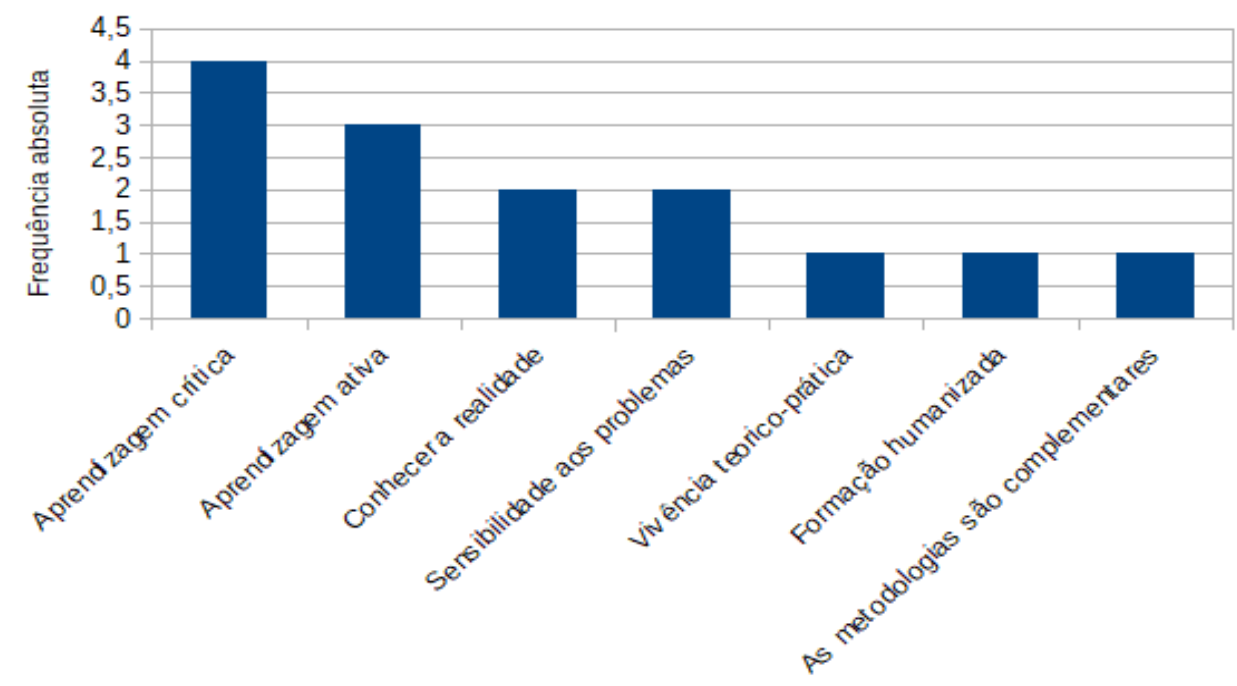

Marin et al. (2010, p. 16) afirma que na ótica dos estudantes, tais métodos, por partirem de situações reais ou que se aproximam da realidade, estimulam o estudo constante, a independência e a responsabilidade do aluno (...). Marin et al. (2010, p. 16) também pontua que na utilização de métodos ativos de aprendizagem, evidencia-se a necessidade de mudança no papel do estudante, que precisa assumir a responsabilidade pela própria aprendizagem. Foi mencionado também por 2 de 13 estudantes que o profissional formado na abordagem da educação problematizadora tem uma maior sensibilidade e destreza para solucionar os problemas do cotidiano. Klein e Ahlert (2019) afirma que

com a utilização de métodos ativos de aprendizagem focados na problematização de
situações reais, de interesse dos alunos, estaremos contribuindo para a formação de
profissionais com condições de promover soluções de problemas de forma autônoma
e colaborativa, atendendo, assim, às demandas do mundo do trabalho. E, ademais, ao
incorporar tais métodos de maneira mais regular nos planos de ensino das instituições
de Educação Profissional, estaremos propiciando com que estas se mantenham no
eixo das constatadas movimentações sociais.

Foi mencionado que nem só as metodologias ativas, isoladas, são capazes de fornecer as habilidades requeridas para a formação profissional do Engenheiro Agrônomo, mas que as abordagens tradicionais também são importantes e podem ser utilizadas de maneira complementar: "Creio que as duas formas podem acrescentar bastante conhecimento ao aluno, podendo as duas serem utilizadas integradas.” (I). Berbel (1995, p. 9) trata do assunto, pontuando que não desejamos anular ou ignorar a importância que tem a exposição em diversas 
situações de ensino. O que é preciso ultrapassar é o seu uso exagerado, o seu uso exclusivo, sem alternativas.

Durante o semestre letivo no qual se desenvolveu esta atividade, houve problemas quanto ao tempo utilizado pela atividade e outros conteúdos que resolveu-se abordar de outra maneira. Dessa forma, foi dado à turma a opção de continuar a atividade com a Metodologia da Problematização, ou com o restante do conteúdo programático. A turma, em maioria, decidiu interromper a atividade com a Metodologia. Foi então questionado aos estudantes através do questionário qual foi o principal motivo pelo qual fizeram esta escolha. Seis de 13 responderam que o motivo foi realmente pela falta de tempo, tendo o receio de que a disciplina encerrasse sem terem visto todo o conteúdo programado. Além desse motivo, 4 de 13 dizem ter dificuldade e falta de costume com a Metodologia. Afirmam: "O costume de usar outras metodologias fez com que eu tivesse dificuldades em aplicá-la sempre." (IX); “A dificuldade de entender certos assuntos ou até mesmo o conformismo com o modelo que é imposto.” (VI). O hábito de ter apenas metodologias de difusão de conhecimento e a falta de costume em serem protagonistas da aprendizagem, traz algumas inseguranças e, até mesmo, a sensação de que as coisas não estão indo como deveriam. Muitos têm dificuldade de entender o que está sendo proposto e ainda muitos apresentam dificuldades em trabalhar em grupo. Sobre isso, Marin et al. (2010, p. 17) afirmam que:

\footnotetext{
pela ótica dos estudantes, encontram-se sentidos que indicam fragilidades no uso de metodologias ativas. Segundo eles, ocorre uma abrupta mudança do método tradicional para as metodologias ativas e, então, sentem-se perdidos na busca de conhecimento, principalmente em disciplinas básicas.

A falta de familiaridade com o método pode despertar nos estudantes a sensação de que não sabem o que deveriam aprender, pelo menos inicialmente.
}

Apesar das dificuldades na execução das atividades e na adaptação dentro dos moldes em que a metodologia foi apresentada, ainda assim 9 dos 13 estudantes indicaram a experiência como positiva, e gostaria de também utilizar a metodologia em outras disciplinas, como mostram as respostas: "Sim, principalmente nas disciplinas que tenho mais dificuldade." (XIII); "Sim, pois é um modo completo de obter um novo senso observatório e crítico." (II). "Sim, foi uma experiência boa, diferente daquelas visitas em outras disciplinas" (VIII). Nenhum estudante relatou não desejar ter outra experiência como esta, porém, 4 não responderam a esta pergunta. É difícil inferir o motivo pelo qual não responderam. 
Como há vários fatores que podem influenciar esta não-resposta, não se considera que estes assumiram uma posição negativa à reaplicação da metodologia.

\section{CONCLUSÃO}

Com este estudo buscou-se evidenciar a Metodologia da Problematização como uma importante ferramenta a contribuir para a formação do profissional de Agronomia, partindo da ideia de que ela pode desenvolver capacidades essenciais ao exercício do agrônomo. Buscamos avaliar a percepção dos estudantes ao serem submetidos a uma experiência do aprendizado que parte da realidade, passando pela construção do conhecimento através da busca autônoma, sua percepção sobre os objetivos e efetivamente quais os benefícios por eles observados.

Em relação à compreensão dos estudantes sobre a metodologia, realizando a comparação das ideias-chave obtidas no questionário com os principais autores que tratam do assunto, verifica-se uma convergência. Para os estudantes, a metodologia é uma forma 'nova' e promissora de aprendizagem que parte da experiência do estudante e da observação de uma realidade, passando por um processo que alia teoria e prática, possibilitando a aquisição de conhecimento e a transformação dos indivíduos nesse processo e, também, da realidade estudada. Apontam que os objetivos da metodologia foram alcançados, desenvolvendo neles senso crítico, uma melhor percepção da realidade estudada, uma forma alternativa de estudar/trabalhar/pesquisar e a possibilidade de adquirir conhecimentos além de sala de aula.

Quanto ao uso da metodologia como alternativa à formação do profissional, a maioria destaca a metodologia como sendo capaz de formar um profissional mais sensível às diferentes realidades, mais humanizado, crítico e capacitado para resolver os problemas por ela impostos. Mostram aceitação à metodologia, apontando o desejo de repetir a experiência até mesmo em disciplinas diferentes da que foi empregada.

Alguns apontaram dificuldades na aplicação da metodologia, o que não foi supressa, pois os estudantes ainda estavam iniciando o estudo das disciplinas profissionalizantes do Curso de Agronomia. Condição esta que pode ter gerado insegurança quanto ao domínio de conteúdos que as situações-problema demandavam.

Sendo assim, a experiência adquirida com a metodologia é satisfatória. Contudo, faz-se necessário um melhor planejamento e dimensionamento da metodologia durante a disciplina de Aspectos Sociais da Agricultura. 


\section{REFERÊNCIAS}

BARDIN, Laurence. Análise de conteúdo. França: Presses Universitaires de France, 1977. 229 p. ISBN 972-44-0898-1.

BARRIOS, Jovita Antonieta Miranda et al (Ed.). Ensino Superior na América Latina: reflexões e perspectivas. Bilbao: Universidad de Deusto, 2014. 57 f. Disponível em: http://www.deusto-publicaciones.es/index.php/main/libro/1088 . Acesso em: 09 jan. 2019.

BERBEL, Neusi Aparecida Navas. Metodologia da Problematização: uma alternativa metodológica apropriada para o Ensino Superior. Semina: Ciências Sociais e Humanas, v.16, n.2, Ed. Especial, p.9-19, out. 1995. Universidade Estadual de Londrina. Disponível em: http://www.uel.br/revistas/uel/index.php/seminasoc/article/viewFile/9458/8240 . Acesso em: 10 jan. 2019

BERBEL, Neusi Aparecida Navas. A problematização e a aprendizagem baseada em problemas: diferentes termos ou diferentes caminhos? Interfase - Comunicação, Saúde, Educação, v.2, n.2, p.139-154, 1998.

BERBEL, Neusi Aparecida Navas. As metodologias ativas e a promoção da autonomia de estudantes. Semina: Ciências Sociais e Humanas, [s.1.], v. 32, n. 1, p.25-40, 20 nov. 2011. Universidade Estadual de Londrina. http://dx.doi.org/10.5433/1679-0359.2011v32n1p25

BERBEL, Neusi Aparecida Navas. O problema de estudo na Metodologia da Problematização . Londrina: [s.n.], 2012. 5 p. Disponível em: http://www.uel.br/pos/mestredu/images/stories/downloads/docentes/conheca_neusi_arq1.pdf . Acesso em: 10 jan. 2019.

CAVALLET, José Valdo. A formação do engenheiro agrônomo em questão: a expectativa de um profissional que atenda as demandas sociais do século XXI. São Paulo, 1999. Tese (Doutorado em Educação). Faculdade de Educação. Universidade de São Paulo.

DIAZ BORDENAVE, Juan E; PEREIRA, Adair Martins. Estratégias de ensinoaprendizagem. Petropolis: Vozes, c1977. 312 p. ISBN 8532601545 (broch.).

GALLAGHER, Kevin. Elementos fundamentales de una Escuela de Campo para Agricultores - ECA. Leisa: Revista de Agroecología, Lima, v. 19, n. 1, p.6-7, jul. 2003. Trimestral. Disponível em: http://www.leisa-al.org/web/index.php/volumen-19-numero-1/2182elementos-fundamentales-de-una-escuela-de-campo-para-agricultores-eca . Acesso em: 01 fev. 2019.

KLEIN, Niumar André; AHLERT, Edson Moacir. Aprendizagem baseada em problemas como metodologia ativa na educação profissional. Revista Destaques Acadêmicos, Lajeado, v. 11, ed. 4, p. 219-239, 2019. DOI http://dx.doi.org/10.22410/issn.21763070.v11i4a2019.2398. Disponível em: http://www.univates.br/revistas/index.php/destaques/article/download/2398/1605. Acesso em: 4 jul. 2020. 
KOLB, David. A. Experiential learning: experience as the source of learning and development. Englewood Cliffs, NJ: Prentice Hall, 1984.

LIBÂNEO, José Carlos. As teorias pedagógicas modernas revisitadas pelo debate contemporâneo na educação. In: LIBÂNEO, José Carlos; SANTOS, Akiko. Orgs. Educação na era do conhecimento em rede e transdisciplinaridade. Campinas, SP: Editora Alínea, 2009.

MARIN, Maria José Sanches et al . Aspectos das fortalezas e fragilidades no uso das metodologias ativas de aprendizagem. Rev. bras. educ. med., Rio de Janeiro, v. 34, n. 1, p. 13-20, Mar. 2010 . Disponível em http://www.scielo.br/scielo.php?script=sci_arttext\&pid=S0100$\underline{55022010000100003 \& \operatorname{lng}=e n \& n r m=i s o}$ Acesso em 09 jan. 2019.

MELO, Barbara de Caldas; SANT'ANA, Geisa. A prática da Metodologia Ativa: compreensão dos discentes enquanto autores do processo de ensino-aprendizagem. Com. Ciências Saúde, Brasília, v. 4, ed. 23, 1 nov. 2012. Disponível em:

http://bvsms.saude.gov.br/bvs/artigos/pratica_metodologia_ativa.pdf. Acesso em: 3 jul. 2020.

PRODANOV, Cleber Cristiano; FREITAS, Ernani Cesar de. Metodologia do Trabalho Científico : Métodos e Técnicas da Pesquisa e do Trabalho Acadêmico. $2^{\mathrm{a}}$. ed. Novo Hamburgo - Rio Grande do Sul - Brasil: Universidade FEEVALE, 2013. 277 p. Disponível em: http://www.feevale.br/Comum/midias/8807f05a-14d0-4d5b-b1ad-1538f3aef538/Ebook\%20Metodologia\%20do\%20Trabalho\%20Cientifico.pdf . Acesso em: 10 jan. 2019.

SAVIANI, Demerval. Escola e democracia: teorias da educação, curvatura da vara, onze teses sobre educação e política. 32 ed. Campinas, SP: Autores Associados, 1999. 99p.

VASCONCELLOS, Maura Maria Morita. Aspectos pedagógicos e filosóficos da metodologia da problematização. In: BERBEL, Neusi Aparecida Navas et al. (Org.). Metodologia da Problematização: fundamentos e aplicações. Londrina: Uel, 1999. p. 29-59. 